\title{
COMBINED ELECTROCHEMICAL PROCESSES FOR THE EFFICIENT DEGRADATION OF NON-POLAR ORGANOCHLORINE PESTICIDES
}

\author{
A. Raschitor, J. Llanos*, M.A. Rodrigo, P. Cañizares \\ Department of Chemical Engineering, Faculty of Chemical Sciences \& Technologies, Ciudad Real, \\ Universidad de Castilla-La Mancha, Ciudad Real 13071, Spain
}

\begin{abstract}
This study deals with the development of efficient and economic electrochemical treatment processes to confront the treatment of liquid wastes containing non-polar organochlorine pesticides. In previous works, it was demonstrated that it is possible to use electrocoagulation (EC) as a concentration technique for a model organochlorine pesticide (oxyfluorfen). Within this framework, the present work describes a process for the degradation of wastes containing non-polar organochlorines (oxyfluorfen or lindane) in two consecutive stages: 1) a first stage of concentration by electrocoagulation; 2) a second stage of electrochemical degradation by electro-oxidation (EO) or electro-Fenton (EF). The first result reached in the present work is that it is possible to remove close to $50 \%$ of both pollutants using EO and more that $94 \%$ using EF. Additionally, it was proved that the addition of a pre-concentration stage decreases by a factor of 20 the power consumption needed to deplete by EO the same amount of the initial pollutant. Moreover, when EF process is performed to the concentrated stream, the power consumption is further reduced, getting values (for $1-\log$ removal) as low as $14.51 \mathrm{kWh} \mathrm{m}^{-3}$ for oxyfluorfen decrease and $49.7 \mathrm{kWh} \mathrm{m}^{-3}$ for lindane. These results strengthen the fact that the removal efficiency increases with the concentration of the pollutant and demonstrate that the combination of concentration steps and electrochemical degradation technologies is an efficient and promising alternative for the degradation of non-polar organochlorines.
\end{abstract}

*Corresponding author: javier.llanos@uclm.es

Keywords: Organochlorine pesticides; BDD; concentration; Electro-oxidation; ElectroFenton 


\section{Introduction}

The climate change and the social development led to a significant increase in the use of organochlorine compounds such as pesticides in order to satisfy the food demand of humans (Aktar et al., 2009; Mall et al., 2017; Regmi, 2015). Agriculture is considered to be the greatest contributor to pesticides contamination in European surface and groundwater (Marianne Köck-Schulmeyer 2013). Various countries in Europe reported that the contamination with pesticides in groundwater surpass the quality standards. According to data reported by the European Environment Agency, about $7 \%$ of the groundwater stations recorded excessive levels for one or more pesticides. This contamination damages the water quality and restricts its use as drinking water. In aquatic ecosystems, elevated concentrations of pesticides may lead to the reduction of population density and to the loss of biodiversity. Nowadays several European water bodies are at risk from diffuse pollution by pesticides (Turan-Ertas and Gurol, 2002). Specifically, oxyfluorfen has been ranked in the top 5 pesticides by cancer hazard factor and has also been classified as an endocrine disruptor (Sugeng et al., 2013), meanwhile the neurotoxicity of lindane has been reported as well as the systemic effects (as depressed liver function and cardiac diseases) related to the chronic exposure to this pesticide (Nolan et al., 2012).

There are many technologies available for the treatment of wastewaters polluted with organochlorine compounds. The bioremediation technique was tested in 2,4-D removal (Sinton et al., 1986) and for several organochlorine compounds (Neilsen, 1996). Recent developments for the removal of 2,4 -D (Carboneras et al., 2017; Chinalia and Killham, 2006; González-Cuna et al., 2016; Sandoval-Carrasco et al., 2013) and for the removal of atrazine by bioremediation-related technologies have been reported in literature (Noor et al., 2014; Wackett et al., 2002). Another interesting alternative for the treatment of wastewater containing organics is the adsorption on granular activated carbon (MuñozMorales et al., 2018). The use of nanoparticles for the removal of this type of pollutants has also been well studied (Patel et al., 2019; Rani et al., 2017; Rawtani et al., 2018). Paknikar et al. used FeS nanoparticles stabilized by biopolymers for the removal of Lindane from aqueous solution (Paknikar et al., 2005). Another interesting application of nanoparticles in the removal of the organochlorine pesticides was seen in the work of Joo and Zhao (Joo and Zhao, 2008) where lindane and atrazine were efficiently removed from wastewater.

Electrochemical oxidation gained a special attention and many researchers focused on the development and integration of this technique. The main advantage of this approach is that the addition of chemicals or other products is not required and that the processes may be easily connected to renewable energy sources (Souza et al., 2015).

The electrochemical oxidation process (Dominguez et al., 2018a, c) showed good results in the treatment of wastewater polluted with lindane wastes and other chlorinated herbicides (Lizama-Bahena et al., 2015). However, the huge volume of wastewater still represents an important problem that urges to be solved. When dealing with high amounts of wastewaters, the size of the equipment and installations increases along with the energy consumption and waste generation. Moreover, by treating high amounts of low 
concentrated wastewater the formation of side reactions and mass transfer limitations are almost impossible to avoid (Comninellis et al., 2008; Panizza et al., 2001).

In order to minimize these limitations, an interesting alternative is the development of concentration strategies, that can be integrated with the main degradation process. Recently, our group begun the study of this approach by applying electrodialysis for the concentration of ionic soluble pesticides (Raschitor et al., 2017) and electrocoagulation for the concentration of insoluble organochlorine compounds (Muñoz et al., 2017).

Based on these previous findings, the present work aims to take a step forward in the development of wastewater treatment technologies by studying the degradation of two of the most used non-polar organochlorine pesticides worldwide, oxyfluorfen and lindane, from a wastewater previously concentrated by electrocoagulation. The degradation was performed by electrochemical oxidation and by electro-Fenton, in the latter case taking advantage of the high concentration of iron of the concentrated solution due to the previous electrocoagulation step. Treatment efficiencies and specific power consumptions were evaluated for all pesticides and technologies tested.

\section{Material and Methods}

\subsection{Materials}

The removal of two different non-polar organochlorines was tested. The first one is oxyfluorfen, that was acquired as the commercial formulation Barre ${ }^{\circledR}$ (Oxyfluorfen 24\%, Solvent naphtha (petroleum) $>25 \%$, Cyclohexanone $<15 \%$ ), provided by a local store named Jovenes Agricultores. As the commercialization of lindane is nowadays forbidden in Spain and there are not commercial formulations available, lindane $\left(\mathrm{C}_{6} \mathrm{H}_{6} \mathrm{C}_{16}, 97 \%\right)$ was purchased pure from Sigma Aldrich.

Sodium Dodecyl Sulfate (SDS) of analytical grade was purchased from Sigma Aldrich (Spain) and used as received. Ethyl Acetate high pure and Acetonitrile were obtained from Sigma Aldrich was used for GC-ECD. Sodium sulfate $100 \%, \mathrm{H}_{2} \mathrm{O}_{2} 37 \%$, hydrochloric acid $37 \%$, sulphuric acid $96 \%$ and $\mathrm{Fe}_{2}\left(\mathrm{SO}_{4}\right)_{3} \cdot \mathrm{x}_{2} \mathrm{O}$ were provided by Panreac and the synthetic wastewater was carefully prepared using ultra-pure miliQ water.

\subsection{Experimental}

The experiments were performed using synthetic wastewaters. For the tests performed with oxyfluorfen, it was prepared a diluted synthetic wastewater containing $100 \mathrm{mg} \mathrm{dm}^{-3}$ oxyfluorfen and $3000 \mathrm{mg} \mathrm{dm}^{-3} \mathrm{Na}_{2} \mathrm{SO}_{4}$. The concentrated wastewater was prepared according to the results obtained in our previous study: $1400 \mathrm{mg} \mathrm{dm}^{-3}$ oxyfluorfen, 3000 $\mathrm{mg} \mathrm{dm} \mathrm{Na}_{2} \mathrm{SO}_{4}$ and $2800 \mathrm{mg} \mathrm{dm}^{-3}$ of $\mathrm{Fe}$ in the form of $\mathrm{Fe}_{2}\left(\mathrm{SO}_{4}\right)_{3}$ (Muñoz et al., 2017).

On the other hand, for the lindane tests it was prepared a diluted synthetic wastewater containing $50 \mathrm{mg} \mathrm{dm}^{-3}$ lindane, $3000 \mathrm{mg} \mathrm{dm}^{-3} \mathrm{Na}_{2} \mathrm{SO}_{4}$ and $10000 \mathrm{mg} \mathrm{dm}^{-3} \mathrm{SDS}$. The concentrated wastewater contains $250 \mathrm{mg} \mathrm{dm}^{-3}$ lindane, $3000 \mathrm{mg} \mathrm{dm}^{-3} \mathrm{Na}_{2} \mathrm{SO}_{4}$ and 2800 $\mathrm{mg} \mathrm{dm}{ }^{-3}$ of $\mathrm{Fe}$ in the form of $\mathrm{Fe}_{2}\left(\mathrm{SO}_{4}\right)_{3}$. 
The electro-oxidation and electro-Fenton tests were conducted using a commercial Adamant Cell equipped with BDD electrodes having a thickness of $2.7 \mu \mathrm{m} \pm 10 \%$, a $\mathrm{sp}^{3} / \mathrm{sp}^{2}$ ratio of $220 \pm 5 \%$ and a boron concentration of $500-700 \mathrm{ppm}$.

The experimentation begun with the preparation of the lab scale experimental setup, that consists in the polarization of the electrochemical cell with $\mathrm{H}_{2} \mathrm{SO}_{4} 20 \%$ followed by a rigorous rinsing with miliQ water.

Electro-oxidation tests were performed at galvanostatic mode and at three current densities: 254.67, 177.33 and $63.6 \mathrm{~A} \mathrm{~m}^{-2}$. At last, Electro-Fenton process was performed by adjusting the $\mathrm{pH}$ at 3.0 followed by the addition of 200 ppm $\mathrm{H}_{2} \mathrm{O}_{2}$ every 10 minutes during the test.

\subsection{Analytical measurements}

COD was determined using COD measurement kits and a Spectroquant Pharo 100 supplied by Merck KGaA (Darmstadt, Germany). Oxyfluorfen concentration was measured by HPLC (Jasco, Japan) after its L-L extraction with Acetonitrile. Acetonitrile/water, 70/30 by volume, was the mobile phase, and the column, a Kinetex $5 \mu \mathrm{m}$ Biphenyl $100 \AA, 150 \times 4.5 \mathrm{~mm}$ (Phenomenex, USA), with an isocratic flow rate of $0.6 \mathrm{~mL} \mathrm{~min}^{-1}$. The UV wavelength was $220 \mathrm{~nm}$ and $20 \mu \mathrm{L}$ of injection volume. To determine lindane concentration in the liquid phase, an $\mathrm{L}-\mathrm{L}$ extraction process was used before the analysis. This process was carried out in separator flasks of $10 \mathrm{~mL}$, using ethyl acetate as extraction solvent (ratio lindane solution/solvent $=1 \mathrm{v} / \mathrm{v}$ is required to extract $100 \%$ of lindane contained in the aqueous phase). After that, all samples extracted from electrolyzed solution were filtered with $0.25 \mu \mathrm{m}$ nylon filters before analysis by Gas Chromatography-Electron Capture Detector (GC ECD) (Thermo Fisher Scientific) using a TG-5MS capillary column $(30 \mathrm{~m} \times 0.25 \mathrm{~mm} 0.25 \mathrm{~mm})$ and $63 \mathrm{Ni}$ micro-electron capture detector, a split/splitless inyector and ChromCard Software. Under the conditions used, the quantification limit of the GC ECD was $0.02 \mathrm{mg} \mathrm{L}^{-1}$. The He flow rate of was $1.0 \mathrm{~mL}$ $\min ^{-1}$. The temperature of the injector was $210^{\circ} \mathrm{C}$. All measurements were performed in triplicate with a relative standard deviation of $3.18 \%$ for oxyfluorfen and $1.54 \%$ for lindane

\section{Results and discussion}

As previously stated in the introduction section, this work aims to demonstrate that the efficiency in the removal of insoluble organochlorines from wastewater (in terms of degradation degree and treatment costs) improves significantly by integrating concentration strategies with electrochemical degradation methods. Basically, the two possible scenarios are schematized in Figure 1. The first one is the direct treatment of a solution polluted with a given non-polar organochlorine compound by electro-oxidation. The second scenario considers performing the treatment in two consecutive stages. The first stage is the concentration of the non-polar organochlorine by electro-coagulation. In this case, the pollutant is concentrated in the solid phase, which can be subsequently dissolved by the addition of an acid as it was tested and explained in our previous work 
(Muñoz et al., 2017). The second step is the treatment of this concentrated stream. In this case, two different alternatives are evaluated: 1) electro-oxidation with BDD anodes and 2) electro-Fenton, taking advantage of the high concentration of iron previously generated in the electrocoagulation stage.

\section{SCENARIO 1}
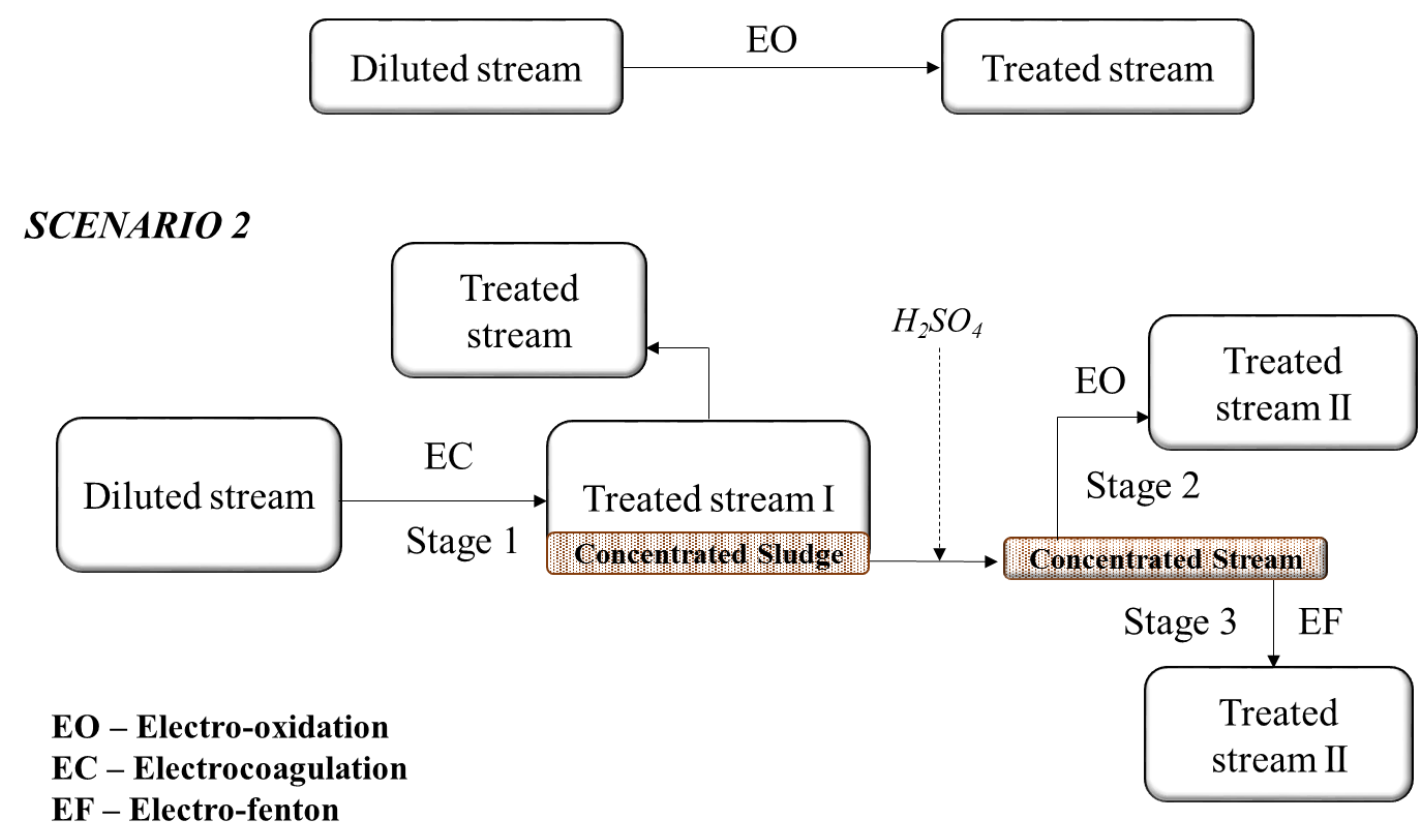

Figure 1. Treatment diagram for the removal of non-polar organochlorines from wastewater

\subsection{Removal of a commercial herbicide containing oxyfluorfen}

The first step of the work consisted in comparing both scenarios previously described for the treatment of a wastewater containing a commercial formulation of a non-polar organochlorine (Barre ${ }^{\circledR}$, containing oxyfluorfen).

\subsubsection{Treatment scenario 1: direct removal by EO}

Thus, Figure 2 presents the results obtained in the removal of oxyfluorfen and COD during the electro-oxidation of a diluted stream at 3 different current density values: 254.7, 177.3 and $63.6 \mathrm{~A} \mathrm{~m}^{-2}$. 

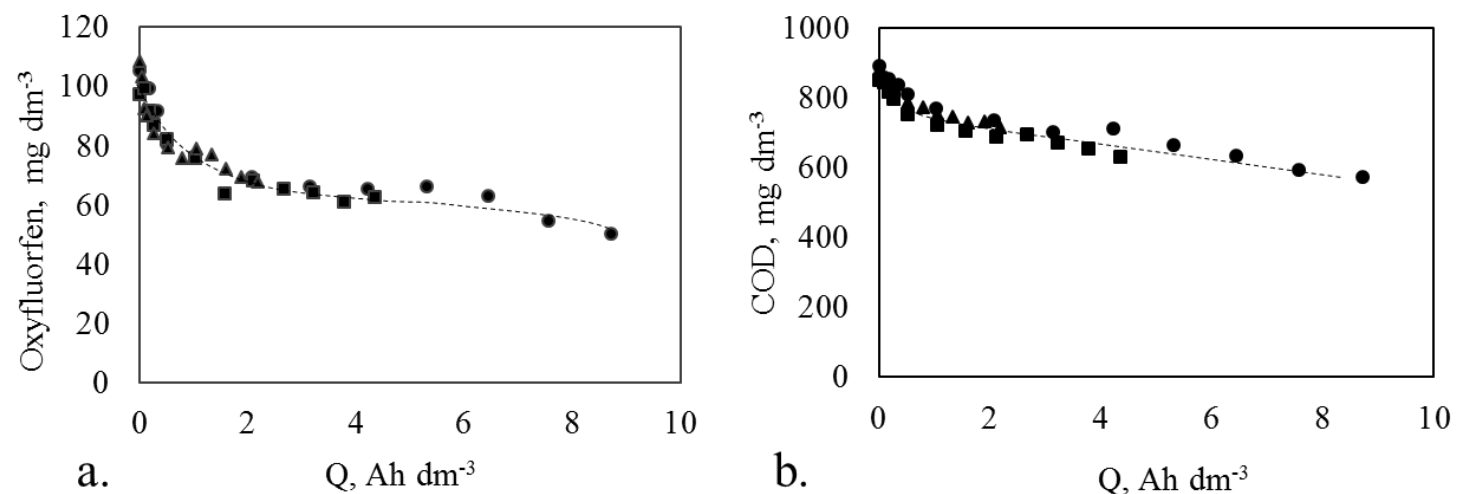

b.

$\mathrm{Q}, \mathrm{Ah} \mathrm{dm}-3$

Figure 2. Influence of the current density applied to a dilute stream on the oxyfluorfen (Figure 2.a) and COD (Figure 2.b) removal $\bullet j=254.7 \mathrm{~A} \mathrm{~m}^{-2}, \mathbf{m} \mathbf{j}=177.3 \mathrm{~A} \mathrm{~m}^{-2}$ and

$$
\mathrm{j}=63.6 \mathrm{~A} \mathrm{~m}^{-2}
$$

At the beginning of the experiment, it can be observed a progressive depletion of the pollutant until getting around 50\% removal of the initial oxyfluorfen concentration. This depletion is performed at two dissimilar removal rates: faster at the beginning of the test and at a lower removal rate when increasing the value of the applied electric charge. This dissimilar rate may be explained by the complex matrix of the target wastewater. As a commercial formulation is used, oxyfluorfen is placed in the solution together with petroleum naphtha (which in turn is a complex mixture of compounds) and cyclohexanone. As it is well-known, the removal of organics by electro-oxidation can be explained by a combination of direct oxidation processes and oxidation mediated by the formation of oxidants (Garcia-Segura et al., 2018; Panizza and Cerisola, 2009; Song et al., 2018), giving a very complex mixture of intermediates specially with the complex initial matrix. Although this behavior should be further studied, the formation of intermediates that are more easily degraded by hydroxyl radicals (Oturan and Aaron, 2014) and the lower availability of oxyfluorfen for lower concentrations (with respect to the rest of organic molecules of the raw stream) may explain the dissimilar removal rates observed.

This hypothesis is consistent with the dissimilar results obtained in a previous work that dealt with the removal of oxyfluorfen from soil washing effluents by electro-oxidation with BDD anodes (dos Santos et al., 2016). This work was confronted by preparing the solutions with pure oxyfluorfen (not a commercial denomination) and by adding increasing concentrations of sodium dodecyl sulphate (SDS) in order to permit the solubilization of oxyfluorfen. It was observed that the removal efficiency of oxyfluorfen increased when higher concentration of SDS were added to the solution, mainly due to the formation of persulphate from the sulphate ions released from the oxidation of SDS, according to Equation 1 (Louhichi et al., 2008; Panizza et al., 2005). A similar explanation was given in the work of Chair et al. that combined biosorption with electrolysis for the removal of oxyfluorfen (Chair et al., 2017). Moreover, in these cases, the water mixed with surfactants drags the minerals and other substances found in soil along with the pollutant. These minerals may favor the formation of oxidant species and enhance the removal efficiency. The influence of the surfactant has been recently studied also on the petroleum elimination using BDD anodes by Escalona-Durán et al. (Escalona-Durán et al., 2019). 


$$
2 \mathrm{SO}_{4}{ }^{2-} \rightarrow 2 \mathrm{~S}_{2} \mathrm{O}_{8}{ }^{2-}+2 \mathrm{e}^{-}
$$

A second noticeable result is that the removal efficiency of oxyfluorfen is similar regardless the value of current density applied, a result that can be explained based on the combination of direct and indirect process that are concurring in the system. On the one hand, if mass transfer limitations are expected when working at low concentration of the pollutant, the removal efficiency of direct oxidation processes is expected to decrease when increasing the current density. On the contrary, the production of oxidants by BDD electrolysis may be promoted at higher values of current densities(Sánchez-Carretero et al., 2011). As the oxidation of organics by the oxidants electrochemically produced is expected to be occurring in the bulk (and thus is not limited by mass transfer to the electrode surface) (He et al., 2019; Vicente et al., 2011), the combined result is a similar value of efficiency regardless the value of the current density applied.

Regarding the removal of COD, it is related to the removal of oxyfluorfen and the rest of organics of the commercial formulation (cyclohexanone and petroleum naphtha) and not only on the main target pollutant. In this case, a removal close to $35 \%$ of the initial COD value is reached at the range of specific charges applied.

\subsubsection{Treatment scenario 2: concentration by electrocoagulation and subsequent degradation technologies.}

Next, the degradation of the concentrated stream previously obtained in an EC process is confronted. In the Figure 3, it can be seen the influence of the current density applied in the removal of oxyfluorfen and COD during the electro-oxidation of a concentrated wastewater at the same values of current density used in the tests with diluted solutions $\left(254.7,177.3\right.$ and $\left.63.6 \mathrm{~A} \mathrm{~m}^{-2}\right)$.
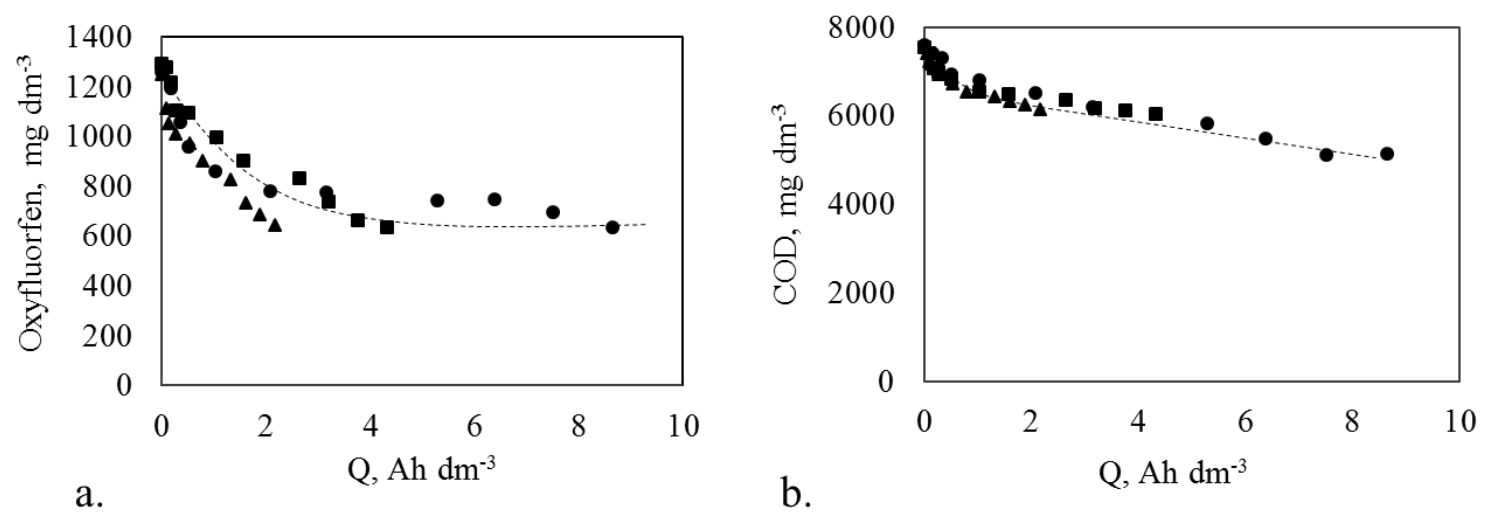

Figure 3. Influence of the current density applied to a concentrated stream on the oxyfluorfen (3.a) and lindane (3.b) removal: $\bullet j=254.67 \mathrm{~A} \mathrm{~m}^{-2}, \boldsymbol{\bullet} \mathrm{j}=177.33 \mathrm{~A} \mathrm{~m}^{-2}$ and

$$
\Delta \mathrm{j}=63.6 \mathrm{~A} \mathrm{~m}^{-2}
$$


As it can be observed, the profile of the degradation of oxyfluorfen is similar to that obtained with diluted solutions: comparable removal efficiency for the different current densities, a maximum of 50\% removal of oxyfluorfen and 30\% COD removal in the range of charge applied and a different rate of oxyfluorfen removal at low and high charge passed. The only difference is a slightly higher efficiency on the removal of oxyfluorfen in the case of the lowest current density, although it cannot be considered noticeable considering the complex matrix analyzed. Nevertheless, it is key to notice that the initial concentration of oxyfluorfen was close to 14 times higher than for the diluted solution but similar degree of removal $(50 \%)$ was obtained for similar values of applied electric charge. This result has a direct impact on the power consumption (Contreras López, 2003), gathered in Figure 5 for diluted and concentrated streams and for a 30\% removal of oxyfluorfen in all cases.

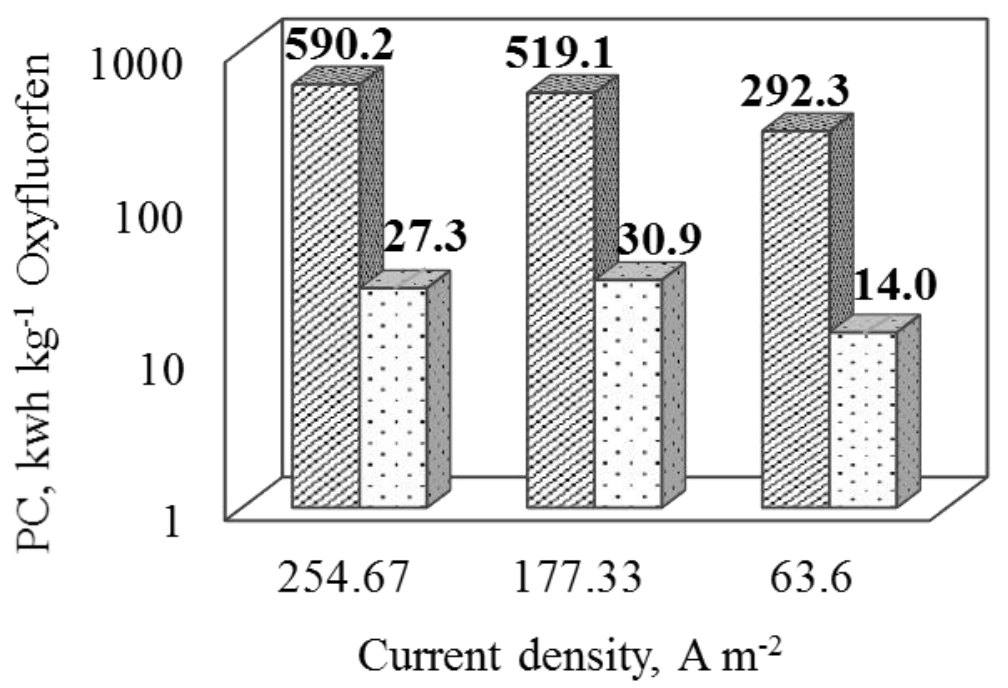

Figure. 4. Influence of the applied current density and the concentration of the solution in the power consumption: grilled-diluted solution $\left(100 \mathrm{mg} \mathrm{dm}^{-3}\right)$ and dottedconcentrated solution $\left(1400 \mathrm{mg} \mathrm{dm}^{-3}\right)$

As expected, the specific power consumption decreases by a factor closely related to the increase in the concentration. The power consumption decreases by a factor of 21.6 for the highest current density, 16.8 for $177.3 \mathrm{~A} \mathrm{~m}^{-2}$ and 20.8 for the lowest value of current density, meanwhile the initial concentration of oxyfluorfen increased by a factor of 14 in all cases. This result was previously found for the concentration of polar organochlorines by our research group (Raschitor et al., 2017) and it is closely related to the higher rate of both direct (influenced by mass transfer) and indirect oxidation processes, both of which depend on the concentration of the target pollutant (Cañizares et al., 2004; Cavalcanti et al., 2013; Hamza et al., 2009; Lanzarini-Lopes et al., 2017). The slight differences between the different current densities are related to the values of the total voltage applied to the cell (average value of $10.2 \mathrm{~V}$ for $254.7 \mathrm{~A} \mathrm{~m}^{-2}$, of $7.9 \mathrm{~V}$ for $177.3 \mathrm{~A} \mathrm{~m}^{-2}$ and $6.1 \mathrm{~V}$ for $\left.63.6 \mathrm{~A} \mathrm{~m}^{-2}\right)$. 
These results are confirming the viability of the approach of scenario 2 for the treatment of oxyfluorfen from the viewpoint of the power consumption. Nevertheless, this operation could not be used as a final treatment technology as there is still a 50\% of the pollutant that it is not removed by electro-oxidation in the range of electric charge applied. To solve this issue, it would be necessary to apply a higher value of applied electric charge or to test a different technology for the electrochemical degradation stage. Thus, the treatment of the concentrated stream was also confronted by electro-Fenton. It is important to highlight that this concentrated solution comes from the previous EC stage, so a high concentration of iron is found in the water effluent and it is only required to add hydrogen peroxide to promote the Fenton reaction.

Thus, Figure 5 represents a comparison between the results obtained by performing the $\mathrm{EO}$ and $\mathrm{EF}$ for the removal of the pollutant from the liquid waste, carried out at the highest value of the current density previously tested for EO $\left(254.7 \mathrm{~A} \mathrm{~m}^{-2}\right)$.

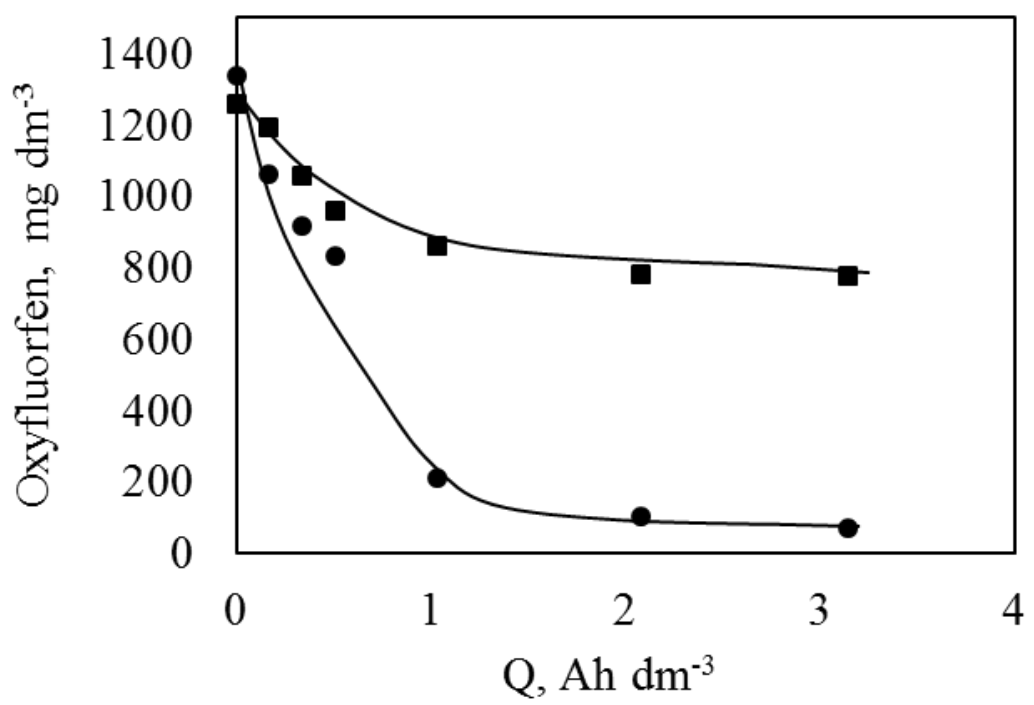

Figure 5. Influence of the treatment on the oxyfluorfen removal at $\mathrm{j}=254.67 \mathrm{~A} \mathrm{~m}^{-2}$. Electro-oxidation• Electro-Fenton.

As it can be clearly observed in Figure 5, promoting the Fenton process by adding $\mathrm{H}_{2} \mathrm{O}_{2}$ to the iron-rich solution has a clear positive effect in the efficiency of the process. In a simplified way, it is considered that in the Fenton process the reaction between $\mathrm{H}_{2} \mathrm{O}_{2}$ and $\mathrm{Fe}^{2+}$ in acid medium $(\mathrm{pH} \leq 3)$ generates hydroxyl radicals $(\mathrm{OH} \bullet)$ according to Equation (2) (Nidheesh and Gandhimathi, 2012). As it can be seen, the removal of oxyfluorfen is faster for the EF process than for the EO, achieving a degradation of oxyfluorfen of $94.8 \%$ for a value of charge of $3.14 \mathrm{Ah} \mathrm{dm}^{-3}$, at which the degradation was lower than $50 \%$ when applying the EO process. The promotion of Fenton process and its combination with BDD electrolysis has been proved efficient in the removal of a wide spectra of organics from both synthetic and real wastewaters (Huguenot et al., 2015; Klidi et al., 2019; Moreira et al., 2017), thus confirming the applicability of this technique to the treatment of the proposed effluents.

$$
\mathrm{Fe}^{2+}+\mathrm{H}_{2} \mathrm{O}_{2} \rightarrow \mathrm{Fe}^{3+}+\mathrm{OH}^{-}+\mathrm{OH} \bullet
$$


The power consumption also decreased compared to EO, reaching a power consumption of $7.55 \mathrm{kWh} \mathrm{kg}^{-1}$ for a $30 \%$ removal of oxyfluorfen. In this case, we have also calculated the energy consumption per order ( $\mathrm{E}_{\mathrm{EO}}$, for a 1-log decrease), a figure of merit that can be more easily compared to other data previously published (Lanzarini-Lopes et al., 2017). This $E_{\mathrm{EO}}$ can be estimated to be $12.04 \mathrm{kWh} \mathrm{kg}^{-1}$, if it is referred to the unit of mass of oxyfluorfen decrease, and to $14.51 \mathrm{kWh} \mathrm{m}^{-3}$, if it is referred to the volume of concentrated solution. This consumption is in the range of the $25^{\text {th }}$ percentile of lowest consumptions reported for electrochemical advanced oxidation process, according to the review recently published by Miklos et al. (Miklos et al., 2018).

\subsection{Applicability of technology for the removal of lindane}

Once established that the EO and EF are suitable and efficient treatment options for the removal of oxyfluorfen, the second part of this work was confronted by using synthetic wastewaters prepared from pure lindane, another non-polar organochlorine herbicide widely used in the past. In order to perform the treatment, lindane was solubilized by adding a proper concentration of SDS as described in the experimental section.

Following the same procedure, the performance of the electro-oxidation process for the removal of lindane, without (scenario 1) and with (scenario 2) previous concentration with electrocoagulation, was tested. The results are presented in Figure 6.

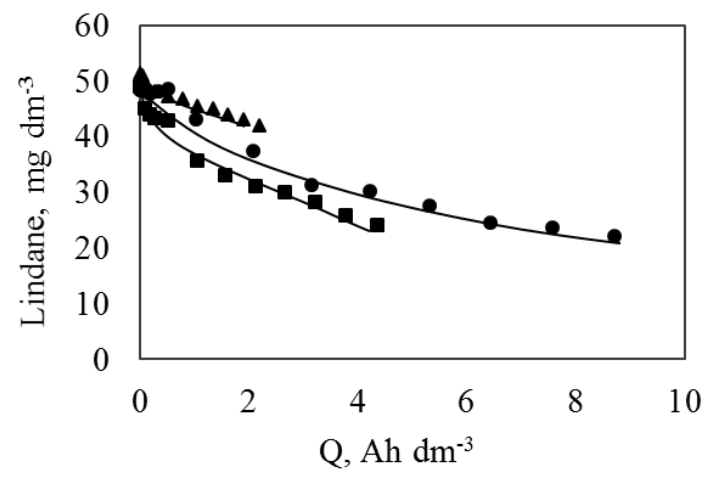

a.

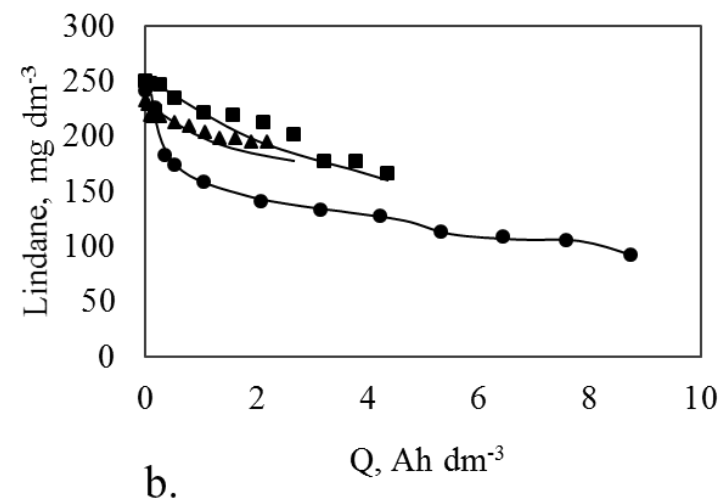

b.

Figure 6. Influence of the current density applied on the lindane removal from diluted (50 ppm, Figure 6.a) and concentrated (250 ppm, Figure 5.b) streams during EO: $\bullet j=$ 254.67 $\mathrm{A} \mathrm{m}^{-2}, \boldsymbol{\Xi}=177.33 \mathrm{~A} \mathrm{~m}^{-2}$ and $\boldsymbol{\Delta} \mathrm{j}=63.6 \mathrm{~A} \mathrm{~m}^{-2}$

As it can be seen, the performance of the process changes when increasing the concentration from 50 to $250 \mathrm{ppm}$. In general terms, the efficiency of the treatment rises when increasing the current density. Nevertheless, for the lowest initial concentration, there is not a noticeable change when increasing the current density from 177.3 to 254.7 $\mathrm{A} \mathrm{m}^{-2}$, meanwhile it does if the test is performed at the highest initial concentration. Moreover, in this case the removal rate is not affected by the amount of charge passed, being the highest removal of lindane (61\%) obtained for a value of applied electric charge of $8.73 \mathrm{Ah} \mathrm{dm}^{-3}$. This behavior is different from that observed in the case of oxyfluorfen 
and may be related to the highest contribution of mediated oxidation processes, that are promoted as the current density increases. This marked contribution of mediated processes must be related to the addition of SDS, as it was previously explained for the removal of oxyfluorfen.

As it was the case for oxyfluorfen removal, the EF process was also applied for the removal of lindane, using the highest value of the current density. The results obtained are presented in Figure 7, meanwhile Figure 8 represents the specific power consumption for a $30 \%$ removal of lindane.

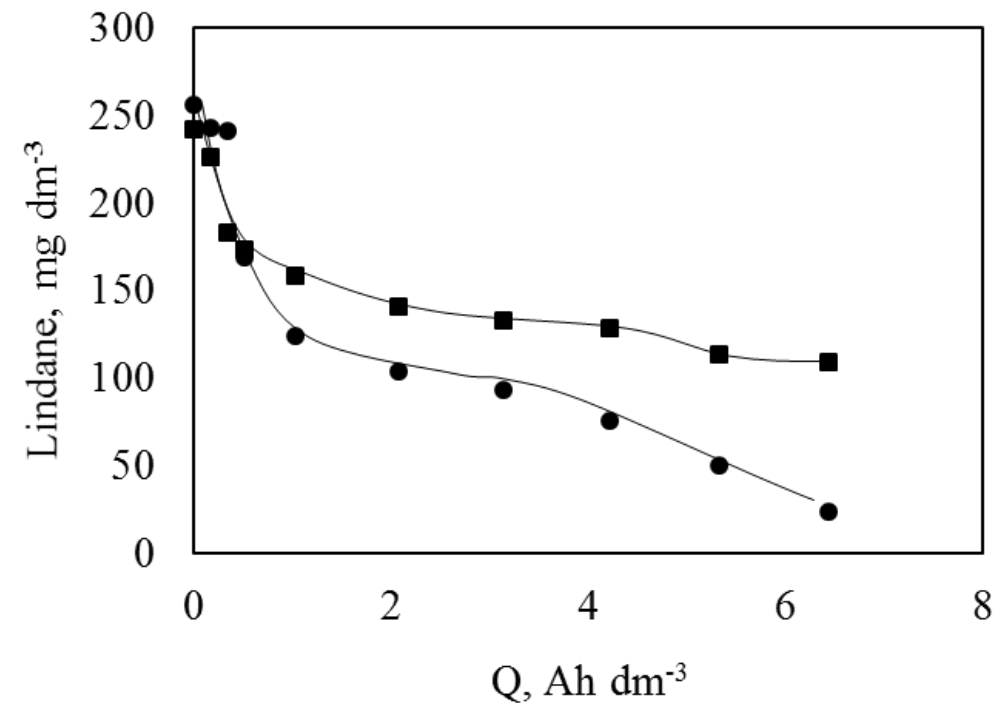

Figure 7. Influence of the treatment on lindane removal at $\mathrm{j}=254.67 \mathrm{~A} \mathrm{~m}^{-2} \mathrm{using}$ : Electro-oxidation • Electro-Fenton

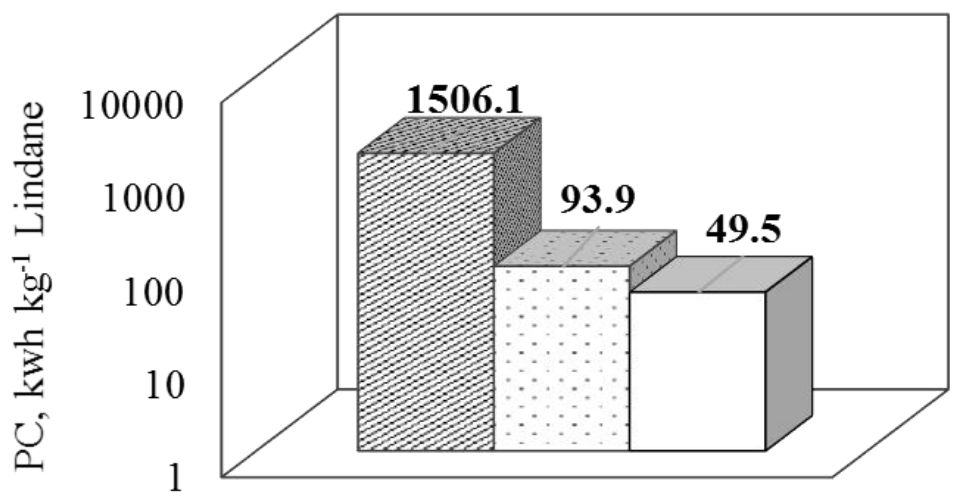

Figure 8. Influence of the current density applied and the concentration on the stream on the energy consumption: grilled - diluted stream; dotted - concentrated stream by EO; empty - concentrated stream by EF. Current density: $254.67 \mathrm{~A} \mathrm{~m}^{-2}$ 
As it can be seen, the performance of both processes is similar in the first part of the test, although the EF process rapidly overcomes the performance of EO for applied charges higher than $1 \mathrm{Ah} \mathrm{dm}^{-3}$. The additional contribution of EF process is noticeable, and it can be observed in terms of power consumption, gathered in Figure 8. In this case, the power consumption is reduced by a factor of 15 , meanwhile the initial concentration was only increased by a factor of 5. Regarding the energy consumption per order, it is estimated to be equal to $214.4 \mathrm{kWh} \mathrm{kg}^{-1}$, if it is referred to the unit of mass of lindane decrease, and to $49.7 \mathrm{kWh} \mathrm{m}^{-3}$, if it is referred to the volume of concentrated solution. This value of power consumption is close to the median of the previously published values for the removal of organics by electrochemical advanced oxidation processes (Miklos et al., 2018) and in the range of those values calculated in works directly devoted to the removal of lindane by EF (Dominguez et al., 2018b). All values obtained are over those calculated for the removal of oxyfluorfen in the line with the lower concentration of the raw effluents selected, thus confirming again the key role of the concentration in the performance of electrochemical degradation technologies. Moreover, the results obtained in this study concerning the decrease in the power consumption when using EF are sustained by the recent review of Bello et al. about the limitation of Fenton reaction and the possible upgrades that can increase the efficiency of this treatment option (Bello et al., 2019).

\section{Conclusions}

From the results presented and discussed in the previous sections, it can be concluded that the following conclusions can be drawn:

- The addition of a concentration step significantly improves the global removal efficiency of electrochemical degradation processes.

- The required power consumption to remove a unit of mass of oxyfluorfen decreased by a factor of 20 when a previous concentration stage by electrocoagulation is applied.

- If an EF process is performed to the concentrated stream, the power consumption is further reduced, getting values for 1-log removal (energy per order) as low as $14.51 \mathrm{kWh} \mathrm{m}^{-3}$, which is within the range of the $25^{\text {th }}$ percentile of lowest consumptions previously reported for electrochemical advanced oxidation process.

- Slight differences are obtained for the treatment of lindane, probably due to the dissimilar matrix of both pollutants: SDS for lindane and petroleum naphtha and cyclohexanone for oxyfluorfen. Nevertheless, a clear increase in the performance of the electrochemical degradation processes is also observed in this case. 


\section{Acknowledgements}

Financial support from the Spanish Ministry of Economy, Industry and Competitiveness and European Union through project CTM2016-76197-R (AEI/FEDER, UE) is gratefully acknowledged.

\section{References}

Aktar, M.W., Sengupta, D., Chowdhury, A., 2009. Impact of pesticides use in agriculture: their benefits and hazards. Interdisciplinary toxicology 2, 1-12.

Bello, M.M., Abdul Raman, A.A., Asghar, A., 2019. A review on approaches for addressing the limitations of Fenton oxidation for recalcitrant wastewater treatment. Process Safety and Environmental Protection 126, 119-140.

Cañizares, P., García-Gómez, J., Lobato, J., Rodrigo, M.A., 2004. Modeling of Wastewater Electro-oxidation Processes Part I. General Description and Application to Inactive Electrodes. Industrial and Engineering Chemistry Research 43, 1915-1922.

Carboneras, B., Villaseñor, J., Fernandez-Morales, F.J., 2017. Modelling aerobic biodegradation of atrazine and 2,4-dichlorophenoxy acetic acid by mixed-cultures. Bioresource Technology 243, 1044-1050.

Cavalcanti, E.B., Garcia-Segura, S., Centellas, F., Brillas, E., 2013. Electrochemical incineration of omeprazole in neutral aqueous medium using a platinum or boron-doped diamond anode: Degradation kinetics and oxidation products. Water Research 47, 18031815.

Chair, K., Bedoui, A., Bensalah, N., Sáez, C., Fernández-Morales, F.J., Cotillas, S., Cañizares, P., Rodrigo, M.A., 2017. Treatment of Soil-Washing Effluents Polluted with Herbicide Oxyfluorfen by Combined Biosorption-Electrolysis. Industrial \& Engineering Chemistry Research 56, 1903-1910.

Chinalia, F.A., Killham, K.S., 2006. 2,4-Dichlorophenoxyacetic acid (2,4-D) biodegradation in river sediments of Northeast-Scotland and its effect on the microbial communities (PLFA and DGGE). Chemosphere 64, 1675-1683.

Comninellis, C., Kapalka, A., Malato, S., Parsons, S.A., Poulios, I., Mantzavinos, D., 2008. Advanced oxidation processes for water treatment: Advances and trends for R\&D. Journal of Chemical Technology and Biotechnology 83, 769-776.

Contreras López, M.C., 2003. Determination of potentially bioaccumulating complex mixtures of organochlorine compounds in wastewater: a review. Environment International 28, 751-759.

Dominguez, C.M., Oturan, N., Romero, A., Santos, A., Oturan, M.A., 2018a. Lindane degradation by electrooxidation process: Effect of electrode materials on oxidation and mineralization kinetics. Water Research 135, 220-230.

Dominguez, C.M., Oturan, N., Romero, A., Santos, A., Oturan, M.A., 2018b. Optimization of electro-Fenton process for effective degradation of organochlorine pesticide lindane. Catalysis Today 313, 196-202.

Dominguez, C.M., Oturan, N., Romero, A., Santos, A., Oturan, M.A., 2018c. Removal of lindane wastes by advanced electrochemical oxidation. Chemosphere 202, 400-409. dos Santos, E.V., Sáez, C., Martínez-Huitle, C.A., Cañizares, P., Rodrigo, M.A., 2016. Removal of oxyfluorfen from ex-situ soil washing fluids using electrolysis with diamond anodes. Journal of Environmental Management 171, 260-266.

Escalona-Durán, F., Villegas-Guzman, P., dos Santos, E.V., da Silva, D.R., MartínezHuitle, C.A., 2019. Intensification of petroleum elimination in the presence of a surfactant using anodic electrochemical treatment with BDD anode. Journal of Electroanalytical Chemistry 832, 453-458. 
Garcia-Segura, S., Ocon, J.D., Chong, M.N., 2018. Electrochemical oxidation remediation of real wastewater effluents - A review. Process Safety and Environmental Protection 113, 48-67.

González-Cuna, S., Galíndez-Mayer, J., Ruiz-Ordaz, N., Murugesan, S., Piña-Escobedo, A., García-Mena, J., Lima-Martínez, E., Santoyo-Tepole, F., 2016. Aerobic biofilm reactor for treating a commercial formulation of the herbicides 2,4-D and dicamba: Biodegradation kinetics and biofilm bacterial diversity. International Biodeterioration \& Biodegradation 107, 123-131.

Hamza, M., Abdelhedi, R., Brillas, E., Sirés, I., 2009. Comparative electrochemical degradation of the triphenylmethane dye Methyl Violet with boron-doped diamond and Pt anodes. Journal of Electroanalytical Chemistry 627, 41-50.

He, Y., Lin, H., Guo, Z., Zhang, W., Li, H., Huang, W., 2019. Recent developments and advances in boron-doped diamond electrodes for electrochemical oxidation of organic pollutants. Separation and Purification Technology 212, 802-821.

Huguenot, D., Mousset, E., van Hullebusch, E.D., Oturan, M.A., 2015. Combination of surfactant enhanced soil washing and electro-Fenton process for the treatment of soils contaminated by petroleum hydrocarbons. Journal of Environmental Management 153, 40-47.

Jones, L.R., Owen, S.A., Horrell, P., Burns, R.G., 1998. Bacterial inoculation of granulaR activated carbon filters for the removal of atrazine from surface water. Water Research 32, 2542-2549.

Joo, S.H., Zhao, D., 2008. Destruction of lindane and atrazine using stabilized iron nanoparticles under aerobic and anaerobic conditions: Effects of catalyst and stabilizer. Chemosphere 70, 418-425.

Klidi, N., Proietto, F., Vicari, F., Galia, A., Ammar, S., Gadri, A., Scialdone, O., 2019. Electrochemical treatment of paper mill wastewater by electro-Fenton process. Journal of Electroanalytical Chemistry.

Lanzarini-Lopes, M., Garcia-Segura, S., Hristovski, K., Westerhoff, P., 2017. Electrical energy per order and current efficiency for electrochemical oxidation of p-chlorobenzoic acid with boron-doped diamond anode. Chemosphere 188, 304-311.

Lizama-Bahena, C., Álvarez-Gallegos, A., Hernandez, J.A., Silva-Martinez, S., 2015. Elimination of bio-refractory chlorinated herbicides like atrazine, alachlor, and chlorbromuron from aqueous effluents by Fenton, electro-Fenton, and peroxi-coagulation methods. Desalination and Water Treatment 55, 3683-3693.

Louhichi, B., Ahmadi, M.F., Bensalah, N., Gadri, A., Rodrigo, M.A., 2008. Electrochemical degradation of an anionic surfactant on boron-doped diamond anodes. Journal of Hazardous Materials 158, 430-437.

Mall, R.K., Gupta, A., Sonkar, G., 2017. 2 - Effect of Climate Change on Agricultural Crops, in: Dubey, S.K., Pandey, A., Sangwan, R.S. (Eds.), Current Developments in Biotechnology and Bioengineering. Elsevier, pp. 23-46.

Marianne Köck-Schulmeyer , M.V., Miren López de Alda, Raquel Céspedes-Sánchez , Francesc Ventura, Damià Barceló 2013. Occurrence and behavior of pesticides in wastewater treatment plants and their

environmental impact. Science of the Total Environment 458 466-476.

Miklos, D.B., Remy, C., Jekel, M., Linden, K.G., Drewes, J.E., Hübner, U., 2018. Evaluation of advanced oxidation processes for water and wastewater treatment - A critical review. Water Research 139, 118-131.

Moreira, F.C., Boaventura, R.A.R., Brillas, E., Vilar, V.J.P., 2017. Electrochemical advanced oxidation processes: A review on their application to synthetic and real wastewaters. Applied Catalysis B: Environmental 202, 217-261. 
Muñoz, M., Llanos, J., Raschitor, A., Cañizares, P., Rodrigo, M.A., 2017. Electrocoagulation as the Key for an Efficient Concentration and Removal of Oxyfluorfen from Liquid Wastes. Industrial and Engineering Chemistry Research 56, 3091-3097.

MuñozMorales, M., Sáez, C., Cañizares, P., Rodrigo, M.A., 2018. A new strategy for the electrolytic removal of organics based on adsorption onto granular activated carbon. Electrochemistry Communications 90, 47-50.

Neilsen, A., 1996. Biodegradation of organochlorine compounds. International Biodeterioration \& Biodegradation 37, 120.

Nidheesh, P.V., Gandhimathi, R., 2012. Trends in electro-Fenton process for water and wastewater treatment: An overview. Desalination 299, 1-15.

Nolan, K., Kamrath, J., Levitt, J., 2012. Lindane toxicity: A comprehensive review of the medical literature. Pediatric Dermatology 29, 141-146.

Noor, S., Changey, F., Oakeshott, J.G., Scott, C., Martin-Laurent, F., 2014. Ongoing functional evolution of the bacterial atrazine chlorohydrolase AtzA. Biodegradation 25, 21-30.

Oturan, M.A., Aaron, J.J., 2014. Advanced oxidation processes in water/wastewater treatment: Principles and applications. A review. Critical Reviews in Environmental Science and Technology 44, 2577-2641.

Paknikar, K.M., Nagpal, V., Pethkar, A.V., Rajwade, J.M., 2005. Degradation of lindane from aqueous solutions using iron sulfide nanoparticles stabilized by biopolymers. Science and Technology of Advanced Materials 6, 370-374.

Panizza, M., Cerisola, G., 2009. Direct and mediated anodic oxidation of organic pollutants. Chemical Reviews 109, 6541-6569.

Panizza, M., Delucchi, M., Cerisola, G., 2005. Electrochemical degradation of anionic surfactants. Journal of Applied Electrochemistry 35, 357-361.

Panizza, M., Michaud, P.A., Cerisola, G., Comninellis, C.H., 2001. Anodic oxidation of 2-naphthol at boron-doped diamond electrodes. Journal of Electroanalytical Chemistry 507, 206-214.

Patel, H., Rawtani, D., Agrawal, Y.K., 2019. A newly emerging trend of chitosan-based sensing platform for the organophosphate pesticide detection using Acetylcholinesterasea review. Trends in Food Science \& Technology 85, 78-91.

Rani, M., Shanker, U., Jassal, V., 2017. Recent strategies for removal and degradation of persistent \& toxic organochlorine pesticides using nanoparticles: A review. Journal of Environmental Management 190, 208-222.

Raschitor, A., Llanos, J., Cañizares, P., Rodrigo, M.A., 2017. Novel integrated electrodialysis/electro-oxidation process for the efficient degradation of 2,4dichlorophenoxyacetic acid. Chemosphere 182, 85-89.

Rawtani, D., Khatri, N., Tyagi, S., Pandey, G., 2018. Nanotechnology-based recent approaches for sensing and remediation of pesticides. Journal of Environmental Management 206, 749-762.

Regmi, A., 2015. Effect of urbanization on global food demand, in: (ERS), D.E.R.S. (Ed.), Changing Structure of Global Food Consumption and Trade Scholar's Choice Washington, pp. 23- 26.

Sánchez-Carretero, A., Sáez, C., Cañizares, P., Rodrigo, M.A., 2011. Electrochemical production of perchlorates using conductive diamond electrolyses. Chemical Engineering Journal 166, 710-714.

Sandoval-Carrasco, C.A., Ahuatzi-Chacón, D., Galíndez-Mayer, J., Ruiz-Ordaz, N., Juárez-Ramírez, C., Martínez-Jerónimo, F., 2013. Biodegradation of a mixture of the 
herbicides ametryn, and 2,4-dichlorophenoxyacetic acid (2,4-D) in a compartmentalized biofilm reactor. Bioresource Technology 145, 33-36.

Sinton, G.L., Fan, L.T., Erickson, L.E., Lee, S.M., 1986. Biodegradation of 2,4-D and related xenobiotic compounds. Enzyme and Microbial Technology 8, 395-403.

Song, H., Yan, L., Jiang, J., Ma, J., Zhang, Z., Zhang, J., Liu, P., Yang, T., 2018. Electrochemical activation of persulfates at BDD anode: Radical or nonradical oxidation? Water Research 128, 393-401.

Souza, F.L., Saéz, C., Llanos, J., Lanza, M.R.V., Cañizares, P., Rodrigo, M.A., 2015. Solar-powered CDEO for the treatment of wastewater polluted with the herbicide 2,4-D. Chemical Engineering Journal 277, 64-69.

Sugeng, A.J., Beamer, P.I., Lutz, E.A., Rosales, C.B., 2013. Hazard-ranking of agricultural pesticides for chronic health effects in Yuma County, Arizona. Science of The Total Environment 463-464, 35-41.

Turan-Ertas, T., Gurol, M.D., 2002. Oxidation of diethylene glycol with ozone and modified Fenton processes. Chemosphere 47, 293-301.

Vicente, F., Santos, A., Romero, A., Rodriguez, S., 2011. Kinetic study of diuron oxidation and mineralization by persulphate: Effects of temperature, oxidant concentration and iron dosage method. Chemical Engineering Journal 170, 127-135.

Wackett, L., Sadowsky, M., Martinez, B., Shapir, N., 2002. Biodegradation of atrazine and related s-triazine compounds: From enzymes to field studies. Applied Microbiology and Biotechnology 58, 39-45. 